\title{
Erratum
}

\section{The $V_{f}$ gene for scab resistance in apple is linked to sub-lethal genes}

\author{
Z.S. Gao ${ }^{1} \&$ W.E. van de $\mathrm{Weg}^{2, *}$ \\ ${ }^{1}$ Department of Horticulture, Huajiachi Campus, Zhejiang University, Hangzhou 310029, P.R. China; ${ }^{2}$ Business \\ Unit Plant Breeding and Biodiversity, Plant Research International, Wageningen University and Research \\ Center, P.O. Box 16, 6700 AA Wageningen, The Netherlands \\ (*author for correspondence: e-mail: eric.vandeweg @wur.nl)
}

Euphytica, DOI: 10.1007/s10681-005-9082-3

An unfortunate error during the production process caused the misrepresentation of Table 2 in the above mentioned article. The cultivars in the first column should have been underlined instead of in italics. The correct reproduction of this Table is published below and should be treated as definitive by the reader:

Table 2. Presence (1) or absence (0) of marker-alleles that are linked in coupling phase to the $V_{f}$-allele for 9 cultivars and 8 molecular markers.

\begin{tabular}{|c|c|c|c|c|c|c|c|c|}
\hline \multirow[b]{2}{*}{ Cultivar } & \multicolumn{8}{|c|}{ Molecular Marker } \\
\hline & $\mathrm{AG} 12_{800}$ & U1-SCAR ${ }^{\mathrm{d}}$ & M18-CAPS ${ }^{d}$ & AL07-SCAR $^{\mathrm{d}}$ & A15 800 & D20-SCAR ${ }^{\mathrm{d}}$ & $\mathrm{C} 09_{900} \mathrm{e}$ & $\overline{\mathrm{AB} 19_{1430}}$ \\
\hline$\underline{S a n t a n a}^{a}$ & 0 & 1 & 1 & 1 & 0 & 0 & 0 & 0 \\
\hline Ecolette & 1 & 1 & 1 & 1 & 1 & 1 & 1 & 1 \\
\hline Topaz & 1 & 1 & 1 & 1 & 1 & 1 & 0 & 0 \\
\hline Priscilla & 0 & 1 & 1 & 1 & $\mathbf{0}$ & $\mathbf{0}$ & $\mathbf{0}$ & 0 \\
\hline$\underline{\text { Prima }}$ & $\mathbf{1}^{\mathrm{b}}$ & 1 & 1 & 1 & 1 & 1 & 1 & 1 \\
\hline$\overline{\text { Idared }}$ & 0 & 0 & 0 & 0 & 0 & 0 & 0 & 0 \\
\hline Braeburn & 0 & 0 & 0 & 0 & 0 & 0 & 0 & 0 \\
\hline Elstar & 0 & 0 & 0 & 0 & 0 & 0 & 0 & 0 \\
\hline M. floribunda 821 & 1 & 1 & 1 & $1^{\mathrm{c}}$ & 1 & 1 & 1 & 1 \\
\hline
\end{tabular}

${ }^{a}$ Underlined genotypes have the resistance gene $V_{f}$.

${ }^{b}$ Data in bold have also been reported by King et al. (1999).

${ }^{\mathrm{c}} M$. floribunda 821 probably has the AL07 allele for $V_{f}$ in homozygous condition.

${ }^{\mathrm{d}}$ For U01-SCAR, AL07-SCAR, and D20, the sizes of the alleles linked to $V_{f}$ are 320, 466, and 500 bps, respectively (Gianfranceschi et al., 1996; Gardiner et al., 1996; Tartarini et al., 1999). M18-CAPS always give a $850 \mathrm{bp}$ fragment. Its allele for $V_{f}$ includes two restriction sites for TaqI (Gianfranceschi et al. 1996).

${ }^{\text {e}}$ Represented by the markers RAPD OPC09-900 and SSR C09 (see Materials \& Methods). The RAPD marker to $V_{f}$ is actually 893 bp after sequencing. 